\title{
Polymerization of L-Alanylglycine with Diphenylphosphoryl Azide
}

\author{
Bun-ichiro NAKAJIMA and Norio NISHI \\ Department of Polymer Science, Faculty of Science, Hokkaido University, \\ Nishi 8-chome, Kita-10-jo, Kita-ku, Sapporo 060, Japan.
}

(Received April 17, 1980)

\begin{abstract}
The polymerization reactions of L-alanylglycine with diphenylphosphoryl azide (DPPA) were investigated under various reaction conditions. Dimethyl sulfoxide and triethylamine were found to be the most suitable solvent and base, respectively, for this polymerization reaction. A reaction time of two days at room temperature, employing 1.3 equivalent moles of DPPA and 2.6 equivalent moles of triethylamine corresponding to the amount of L-alanylglycine were considered to be the most appropriate reaction condition. In this case, poly(L-alanylglycine) which has the intrinsic viscosity of 0.16 in dichloroacetic acid at $25^{\circ} \mathrm{C}$ was obtained in $43 \%$ yield. Its infrared absorption spectrum and elemental analysis, and the amino acid analysis or the optical rotation for the acid hydrolysate indicated the high purity of poly(L-alanylglycine) obtained by this DPPA method.
\end{abstract}

KEY WORDS Diphenylphosphoryl Azide / L-Alanylglycine / Polymerization / Poly(L-alanylglycine) / Intrinsic Viscosity / Infrared Absorption Spectrum /

Diphenylphosphoryl azide (DPPA) has been used as a convenient reagent for racemization-free peptide synthesis since it was synthesized by Shioiri et al. in $1972 .{ }^{1}$ It is non-explosive and stable enough to be stored for a long time without decomposition.

Recently, we reported that this reagent can also be used successfully for the polymerization of amino acids or peptides. ${ }^{2}$ A polypeptide can easily be prepared by just stirring the solution or suspension of amino acid or peptide in a suitable solvent with DPPA and a tertiary amine such as triethylamine. Poly(amino acid)s such as poly(glycine), poly(Lalanine), poly(L-leucine), poly( $\gamma$-benzyl L-glutamate), $\operatorname{poly}(\varepsilon$-benzyloxycarbonyl-L-lysine), $\operatorname{poly}(\beta$ alanine) and poly(6-aminohexanoic acid) were prepared by this method. ${ }^{2}$ Sequential polypeptides such as poly(L-alanylglycine), poly(L-alanylglycyl-Lalanylglycyl-L-alanylglycyl-L-serylglycine), $\operatorname{poly}(O$ benzyl-L-seryl- $\beta$-alanylglycyl-L-histidyl- $\beta$-alanylglycine $)$, and poly $(\beta$-benzyl-L-aspartyl- $\beta$-alanylglycyl- $O$-benzyl-L-seryl- $\beta$-alanylglycyl-L-histidyl- $\beta$ alanylglycine) were also synthesized successfully, as previously reported. ${ }^{2}$ In particular, the polymerization of L-histidine-containing hexa- or nonapeptide gave a high-molecular-weight sequential polypeptide. Thus the DPPA method seems to have the possibility of becoming one of the very convenient and efficient methods for polypeptide synthesis, especially for the synthesis of sequential polypeptides, if the further exhaustive investigation is performed. In developing this method of polymerization, it would be very helpful to investigate in detail the relationship between the reaction conditions and results, using one kind of peptide as a representative.

In the present study, the polymerization of Lalanylglycine was investigated in detail to find the most suitable reaction conditions for this peptide and, as a result, useful information by which this DPPA method could be used for the general synthesis of sequential polypeptides was obtained. The detailed study on the composition or the purity of resultant poly(L-alanylglycine) are also reported.

\section{EXPERIMENTAL}

\section{Measurements}

Elemental analyses were carried out with a Yanagimoto CHN Corder, Model MT-2. Optical rotations were measured with a Yanagimoto 
Automatic Recording Polarimeter, Model OR-1. Amino acid analysis was performed with a JEOL Amino Acid Analyser, JLC-6AH. None of the melting points were corrected. Intrinsic viscosities were measured with a Ostwald-type viscometer in dichloroacetic acid (DCA) at $25^{\circ} \mathrm{C}$. Infrared absorption spectra were measured with $\mathrm{KBr}$ pellets on a Hitachi Grating Infrared Spectrophotometer, EPI-G-2.

\section{Reagents and Solvents}

Diphenylphosphoryl azide (DPPA) and triethylamine (special grade) were purchased from Daiichi Pure Chemicals Co., Ltd. and Wako Pure Chemical Industries Ltd., respectively, and were used without further purification. Dimethyl sulfoxide (DMSO) and other solvents were purified by adequate procedures, including distillation.

\section{Monomer Peptides}

L-Alanylglycine (H-Ala-Gly-OH). ${ }^{3}$ This compound was prepared by the catalytic hydrogenation of benzyloxycarbonyl-L-alanylglycine (Z-Ala-Gly$\mathrm{OH}) .^{4} \mathrm{mp} 230 \mathrm{C}(\mathrm{dec}),[\alpha]_{\mathrm{D}}^{20}+52.7^{\prime \prime}\left(c, 20 \mathrm{gl}^{-1}\right.$, $\mathrm{H}_{2} \mathrm{O}$ ).

Anal. Calcd for $\mathrm{C}_{5} \mathrm{H}_{10} \mathrm{O}_{3} \mathrm{~N}_{2}: \mathrm{C}, 41.07 \% ; \mathrm{H}$, $6.90 \% ; \mathrm{N}, 19.17 \%$. Found: C, $40.82 \% ; \mathrm{H}, 6.92 \% ; \mathrm{N}$, $18.92 \%$

Lit. ${ }^{3} \mathrm{mp} 230-231.5^{\circ} \mathrm{C}(\mathrm{dec}),[\alpha]_{\mathrm{D}}+50.3^{\circ}(c, 20$ $\left.\mathrm{gl}^{-1}, \mathrm{H}_{2} \mathrm{O}\right)$.

L-Alanylglycyl-L-alanylglycine $\quad(H$-Ala-Gly-AlaGly-OH). This compound was also prepared by the catalytic hydrogenation of benzyloxycarbonyl-Lalanylglycyl-L-alanylglycine (Z-Ala-Gly-Ala-Gly$\mathrm{OH})$. Z-Ala-Gly-Ala-Gly-OH $(502 \mathrm{mg})^{5}$ in a mixture of methanol $(20 \mathrm{ml})$ and $50 \%$ aqueous acetic acid $(40 \mathrm{ml})$ was hydrogenated over $5 \%$ palladiumcarbon $(400 \mathrm{mg})$ at room temperature for $4.5 \mathrm{~h}$. The reaction mixture was filtered so as to remove the catalyst, and the solvents were evaporated to dryness. The treatment with ethanol gave a crystalline product. Recrystallized from waterethanol; yield, $280 \mathrm{mg}\left(83^{\circ} \%\right) ; \mathrm{mp} 239^{\circ} \mathrm{C}(\mathrm{dec}) ;[\alpha]_{\mathrm{D}}^{28}$ $-33.4^{\circ}\left(c, 5.4 \mathrm{gl}^{-1}, \mathrm{H}_{2} \mathrm{O}\right)$.

Anal. Calcd for $\mathrm{C}_{10} \mathrm{H}_{18} \mathrm{O}_{5} \mathrm{~N}_{4} \cdot 0.5 \mathrm{H}_{2} \mathrm{O}: \mathrm{C}, 42.38 \%$; $\mathrm{H}, 6.76 \%$; N, $19.78 \%$. Found: C, $42.40 \%$; H, $6.53 \%$; $\mathrm{N}, 19.58 \%$.

Glycyl-L-alanine (H-Gly-Ala-OH). ${ }^{6}$ This compound was purchased from Sigma Chemical Company, U.S.A.

\section{Polymerizations}

Polymerizations of $\mathrm{L}$-Alanylglycine under Various Conditions. To stirred suspensions of H-Ala-Gly$\mathrm{OH}(200 \mathrm{mg})$ in DMSO or some other solvent were added DPPA and triethylamine or another base. These mixtures were stirred for $1 \mathrm{~h}$ at $5-8^{\circ} \mathrm{C}$ followed by stirring under various reaction conditions. Variation in the reactions was made by changing the amounts of solvent or reagents, reaction time and other reaction condtions. Some of the reaction mixtures were heated at $90^{\circ} \mathrm{C}$ for $1 \mathrm{~h}$ before being worked up in order to complete the polymerization. The polymers were precipitated by the addition of water $(80 \mathrm{ml})$, centrifuged and washed with water, $(\times 3)$, ethanol, $(\times 3)$, and ether, $(\times 1)$. They were dried in vacuo. Their yields and intrinsic viscosities in DCA at $25^{\circ} \mathrm{C}$ were compared with each other.

Preparation of Poly(L-alanylglycine) by the Most Suitable Reaction Condition. L-Alanylglycine $(504 \mathrm{mg}, 3.45 \mathrm{mmol})$ was polymerized in DMSO $(1.0 \mathrm{ml})$ using DPPA $(0.96 \mathrm{ml}, 4.49 \mathrm{mmol})$ and triethylamine $(1.26 \mathrm{ml}, 8.97 \mathrm{mmol})$ for 2 days at room temperature. Yield $179 \mathrm{mg}(41 \%),[\eta]=0.16$ (in DCA, $\left.25^{\circ} \mathrm{C}\right)$. This crude poly(L-alanylglycine) was reprecipitated from DCA-water, followed by washing with water, ethanol, and ether. Yield, $108 \mathrm{mg}(24 \%)$. The purity checks described below were performed using this reprecipitated polymer.

Polymerization of $\mathrm{L}$-Alanylglycyl-L-alanylglycine. The tetrapeptide, H-Ala-Gly-Ala-Gly-OH $(197 \mathrm{mg}$, $0.72 \mathrm{mmol})$, was polymerized in DMSO $(0.4 \mathrm{ml})$ with DPPA $(0.20 \mathrm{ml}, 0.94 \mathrm{mmol})$ and triethylamine $(0.27 \mathrm{ml}, 1.90 \mathrm{mmol})$ by the same procedures as in the case of H-Ala-Gly-OH polymerization. Yield, $86 \mathrm{mg}(47 \%),[\eta]=0.17$ (in DCA, $25^{\circ} \mathrm{C}$ ).

Polymerization of Glycyl-L-alanine. Glycyl-Lalanine $(500 \mathrm{mg}, 3.42 \mathrm{mmol})$ was polymerized in DMSO (1 ml) with DPPA $(0.95 \mathrm{ml}, 4.45 \mathrm{mmol})$ and triethylamine $(1.25 \mathrm{ml}, 8.89 \mathrm{mmol})$ by the same procedures used for H-Ala-Gly-OH polymerization. Yield, $314 \mathrm{mg}(72 \%)$. This crude poly(glycyl-Lalanine) was reprecipitated from DCA-water, followed by washing with water, methanol and ether. Yield, $230 \mathrm{mg}(52 \%)$. An optical-purity check, described below, was performed using this reprecipitated polymer in comparison with the polymer obtained by the H-Ala-Gly-OH polymerization.

Examinations for the Purity of Poly(L-alanylglycine) 
Phosphorus Test. The presence of phosphorus compound was tested by the well-known method of using molybdate reagent.

Elemental Analysis. The results of elemental analysis are as follow.

Anal. Calcd for $\left(\mathrm{C}_{5} \mathrm{H}_{8} \mathrm{O}_{2} \mathrm{~N}_{2} \cdot 0.2 \mathrm{H}_{2} \mathrm{O}\right)_{n}$ : C, $45.57 \%$; H, $6.43 \%$; N, $21.27 \%$. Found: $\mathrm{C}, 45.85 \%$; $\mathrm{H}, 6.48 \%$; N, $21.06 \%$.

Amino Acids Composition. The amino acid analysis for the acid hydrolysate: Ala 1.00, Gly 0.97 $(92 \%)$. The acid hydrolysate was also submitted to both silica-gel thin-layer chromatography (Merck Kieselgel G) and paper chromatography, using the Partridge system (1-butanol : acetic acid : water $=$ $4: 1: 5$, upper layer) and pyridine system (1-butanol : pyridine : acetic acid : water $=15: 10: 3$ : 12).

Optical Purity. Poly(L-alanylglycine) $(54.5 \mathrm{mg}$, contains $0.414 \mathrm{mmol}$ of L-Ala and Gly) was hydrolyzed in $6 \mathrm{~N} \mathrm{HCl}(7 \mathrm{ml})$ at $110^{\circ} \mathrm{C}$ for $20 \mathrm{~h}$. The mixture of L-alanine $(36.9 \mathrm{mg}, 0.414 \mathrm{mmol})$ and glycine $(31.1 \mathrm{mg}, 0.414 \mathrm{mmol})$ in $6 \mathrm{~N} \mathrm{HCl}(7 \mathrm{ml})$ was also heated under the same conditions as for the polymer solution. The optical rotation of the hydrolysate solution was compared with that of a standard solution, using a quartz cell of $0.5 \mathrm{dm}$ length. $\chi$ (hydrolysate soln), $+0.034 ; \chi$ (standard soln), +0.033 . The optical purity of poly(glycyl-Lalanine) obtained by the H-Gly-Ala-OH polymerization was also examined in a similar way. Poly(glycyl-L-alanine) (102.5 mg, contains 0.778 $\mathrm{mmol}$ of Gly and L-Ala) was hydrolyzed in $6 \mathrm{~N} \mathrm{HCl}$ $(7 \mathrm{ml})$ at $110^{\circ} \mathrm{C}$ for $20 \mathrm{~h}$. The mixture of glycine $(58.3 \mathrm{mg}, 0.778 \mathrm{mmol})$ and $\mathrm{L}$-alanine $(69.5 \mathrm{mg}, 0.778$ $\mathrm{mmol})$ in $6 \mathrm{~N} \mathrm{HCl}(7 \mathrm{ml})$ was also heated similarly. $\chi$ (hydrolysate soln), $+0.064 ; \chi$ (standard soln), +0.068 .

Infrared Absorption Spectra. The infrared absorption spectra of crude and reprecipitated polymes, and the polymer obtained by treating crude poly(L-alanylglycine) in $1 \%$ aqueous triethylamine at $90^{\circ} \mathrm{C}$ for $1 \mathrm{~h}$ were compared with each other, and also with that of poly(L-alanylglycine $)^{5}$ prepared by pentachlorophenyl ester method.

\section{RESULTS AND DISCUSSION}

\section{Polymerization in DMSO-Triethylamine System}

Many kinds of polymerization reactions of $\mathrm{L}-$ alanylglycine were carried out using DMSO and triethylamine as a representative solvent and base, respectively, to determine optimum polymerization reaction conditions such as the most suitable amount of the reagent or solvent, reaction time and reaction temperature. The polymers were worked up by procedures involving precipitation with water and ethanol. Treatment with water removed the small peptides having free carboxyl or amino ends. But treatment with ethanol removed the cyclized small peptides such as diketopiperazine. A qualitative examination of the mother liquors, using thinlayer chromatography, suggested that the materials removed during the working up process were mainly peptides or polypeptides of low molecular weight, and the amount of diketopiperazine seemed not to be so predominant. The yields from the polymerization reactions and the intrinsic viscosities of the polymers as a rough criteria of molecular weight are listed in Table I along with the reaction conditions. From the results summarized in Table I, the following conclusion were obtained.

a) At least ca. 1.3 equiv mol of DPPA to the amount of L-alanylglycine is necessary for the efficient polymerization. (See No. 1, 2, and 3).

b) The most suitable amount of triethylamine is ca. 2.6 equiv mol to the amount of the monomer peptide. (Compare No. 5, 7 and 8 with each other).

c) A reaction time of two days is sufficient in the case of polymerization reactions at room temperature. (Compare No. 2 with 5, and No. 4 with 6).

d) No heating procedure for the completion of polymerization is necessary. (Compare No. 2 with 4 , and No. 5 with 6).

e) Repolymerization by the supplemental addition of reagents scarcely improves the results. (Compare No. 9 with 7).

f) In regard to the amount of DMSO, $0.4 \mathrm{ml}$ is adequate for $200 \mathrm{mg}$ of $\mathrm{H}$-Ala-Gly-OH. The use of a larger amount of solvent causes a decrease in yield and in molecular weight. (Compare No. 10 or 11 with 7).

g) Room temperature $\left(15-25^{\circ} \mathrm{C}\right)$ is preferable to higher or lower reaction temperatures. (Compare No. 12,13 or 14 with 7.)

To obtain pure polymers of high molecular weight in good yield, a coupling reaction would be efficient and not accompanied by any side reactions. In addition, intermolecular coupling reactions (polymerization) would be far more predominant than intramolecular coupling reactions (cycliza- 
Table I. Polymerizations of L-alanylglycine in DMSO-triethylamine system

\begin{tabular}{|c|c|c|c|c|c|c|c|}
\hline \multirow{2}{*}{ No. } & \multirow{2}{*}{$\frac{\mathrm{DMSO}}{\mathrm{ml}}$} & \multirow{2}{*}{$\frac{\text { DPPA }^{\mathrm{a}}}{\text { equiv mol }}$} & \multirow{2}{*}{$\frac{\text { TEA }^{\mathrm{a}}}{\text { equiv mol }}$} & \multirow{2}{*}{$\frac{\mathrm{Temp}^{\mathrm{b}}}{{ }^{\circ} \mathrm{C}}$} & \multirow{2}{*}{$\frac{\text { Time }}{\text { day }}$} & \multirow{2}{*}{$\frac{\text { Yield }}{\%}$} & \multirow{2}{*}[\eta]{$^{\mathrm{d}}$} \\
\hline & & & & & & & \\
\hline 1 & 0.4 & 1.1 & 1.1 & r.t. & 5 & 19 & 0.14 \\
\hline 2 & 0.4 & 1.3 & 1.3 & r.t. & 5 & 28 & 0.15 \\
\hline 3 & 0.4 & 1.5 & 1.5 & r.t. & 5 & 27 & 0.13 \\
\hline 4 & 0.4 & 1.3 & 1.3 & r.t. ${ }^{\mathrm{c}}$ & 5 & 26 & 0.15 \\
\hline 5 & 0.4 & 1.3 & 1.3 & r.t. & 2 & 29 & 0.14 \\
\hline 6 & 0.4 & 1.3 & 1.3 & r.t. ${ }^{\mathrm{c}}$ & 2 & 33 & 0.14 \\
\hline 7 & 0.4 & 1.3 & 2.6 & r.t. & 2 & 43 & 0.16 \\
\hline 8 & 0.4 & 1.3 & 6.5 & r.t. & 2 & 40 & 0.14 \\
\hline 9 & 0.4 & $1.3+1.3$ & $2.6+2.6$ & r.t. & $2+2$ & 50 & 0.15 \\
\hline 10 & 0.8 & 1.3 & 2.6 & r.t. & 2 & 24 & 0.15 \\
\hline 11 & 1.2 & 1.3 & 2.6 & r.t. & 2 & 22 & 0.14 \\
\hline 12 & 0.4 & 1.3 & 2.6 & $40-45$ & 2 & 30 & 0.14 \\
\hline 13 & 0.4 & 1.3 & 2.6 & $5-10$ & 2 & 31 & 0.14 \\
\hline 14 & 0.4 & 1.3 & 2.6 & $5-10$ & 5 & 31 & 0.15 \\
\hline
\end{tabular}

a Equivalent moles of DPPA or triethylamine (TEA) to the amount of L-alanylglycine $(200 \mathrm{mg})$.

b r.t., room temperature.

c Heated at $90^{\circ} \mathrm{C}$ for $1 \mathrm{~h}$ at end of polymerization time.

d Measured in DCA at $25^{\circ} \mathrm{C}$.

tion). Once a cyclization reaction occurs, the polymerization might be stopped at the same time. All reaction conditions, such as the amount of the solvent and reagents or reaction temperature, will certainly affect this matter. In regard to the amount of solvent, for example, the polymerization reaction in a large amount of solvent is not preferable because this might cause predominancy of the cyclization reaction. However, the use of too small an amount of solvent might cause heterogeneity of the reaction.

As a final conclusion regarding the results of the experiments, the reaction conditions, involving a reaction time of two days at room temperature and employing $0.4 \mathrm{ml}$ of DMSO, 1.3 equiv mol of DPPA and 2.6 equiv mol of triethylamine to $200 \mathrm{mg}$ of $\mathrm{H}$ Ala-Gly-OH, were considered to be most suitable. However, it is also found that a small change in the reaction conditions does not greatly alter the results when the DMSO-triethylamine system is used.

\section{Polymerization to Use Other Solvents or Bases}

The polymerization reactions of L-alanylglycine in various kinds of solvents were carried out with triethylamine ( 1.3 equiv mol) as a base for finding the most adequate solvent for polymerization.
Table II. Polymerizations of L-alanylglycine in various kinds of solvents employing triethylamine as a base: H-Ala-Gly-OH, 200 mg; DPPA, 1.3 equiv mol; triethylamine, 1.3 equiv mol; solvent, $0.4 \mathrm{ml}$; reaction time, 2 days at room temperature

\begin{tabular}{|c|c|c|c|}
\hline No. & Solvent ${ }^{\mathrm{a}}$ & $\frac{\text { Yield }}{\%}$ & {$[\eta]^{\mathrm{b}}$} \\
\hline 1 & HMPA & 6 & - \\
\hline 2 & DMA & Trace & - \\
\hline 3 & Pyridine & 15 & 0.16 \\
\hline 4 & Pyrrolidone & 22 & 0.13 \\
\hline 5 & Me-Pyrrolidone & 22 & 0.13 \\
\hline 6 & Dioxane & 5 & - \\
\hline 7 & TCE & Trace & - \\
\hline 8 & DCE & Trace & - \\
\hline 9 & Anisole & Trace & - \\
\hline 10 & DMSO & 29 & 0.14 \\
\hline
\end{tabular}

a Abbreviations: HMPA, hexamethylphosphoramide; DMA, dimethylacetamide; Me-, methyl-; TCE, tetrachloroethane; DCE, dichloroethane.

b See Table I.

Polymerizations using various kinds of bases were 
Table III. Polymerizations of L-alanylglycine employing various kinds of bases: H-Ala-Gly-OH, $200 \mathrm{mg}$; DPPA, 1.3 equiv mol; solvent, DMSO $(0.4 \mathrm{ml})$; reaction time, 2 days at room temperature

\begin{tabular}{clrc}
\hline & & Yield & \\
\cline { 3 - 3 } No. & Base, ${ }^{\text {a }}$ equiv mol & & \\
& & $\%$ & \\
& & \multicolumn{1}{c}{]$^{\mathrm{b}}$} \\
\hline 1 & $\mathrm{CH}_{3} \mathrm{ONa}, 1.5$ & 1 & - \\
2 & $\mathrm{Na}-\mathrm{HGMB}, 1.5$ & 2 & - \\
3 & $\mathrm{TBA}, 2.6$ & 23 & 0.12 \\
4 & $\mathrm{DMe}-$ aniline, 2.6 & 0 & - \\
5 & $\mathrm{TEA}, 2.6$ & 43 & 0.16 \\
\hline
\end{tabular}

a Abbreviations: Na-HGMB, sodium hexyleneglycol monoborate; TBA, tributylamine; DMe-, dimethyl-.

b See Table I.

also investigated in DMSO. The results are summarized in Tables II and III, respectively. The polymerization reactions in pyridine, pyrrolidone or $\mathrm{N}$-methylpyrrolidone gave similar or slightly inferior results compared to that in DMSO. However, the use of other solvents such as DMA, tetrachloroethane or dioxane gave only a very small amount of polymer. On the other hand, the use of other bases gave bad results, though the reaction employing tributylamine was not so bad.

After all, no solvent or base could be found that was much better than DMSO or triethylamine. The reaction in DMSO employing triethylamine as a base seems to be the most preferable for the polymerization of L-alanylglycine.

\section{Comparison of H-Ala-Gly-OH Polymerizations with \\ Those of Longer Peptides}

The polymerization of tetrapeptide, L-alanylglycyl-L-alanylglycine, gave almost the same or slightly better results (polymer of $[\eta]=0.17$ in $47 \%$ yield) than the polymerization of dipeptide (polymer of $[\eta[=0.16$ in $43 \%$ yield). However, the polymerization of a longer peptide with a similar amino acid sequence, H-Ala-Gly-Ala-Gly-Ala-GlySer-Gly-OH, gave a polymer of lower molecular weight in better yield as previously reported (polymer of $[\eta]=0.13$ in $52 \%$ yield). ${ }^{2,5}$ The polymerization of a longer peptide might be much more advantageous than that of dipeptide since the amount of triethylammonium salt of diphenylphos- phoric acid, derived from DPPA during the reaction, is smaller and there is no possibility to produce diketopiperazine. As a matter of fact, the polymerization of a dipeptide gave results similar to those obtained for longer peptides. On the other hand, the polymerization of L-histidine containing hexa- or nona-peptide gave a sequential polypeptide having a much greater molecular weight in good yield. ${ }^{2}$ The peptide or polypeptide of repeating -AlaGly- sequence is known to be sparingly soluble in various organic solvents. The biggest factor which limits the proceeding of the polymerization might be the solubility of the elongating polypeptide chain in the case of the polymerization of the peptide with -Ala-Gly- sequence.

\section{Infrared Absorption Spectra}

The infrared absorption spectra of poly(Lalanylglycine)s (crude and reprecipitated) were compared with those of poly(L-alanylglycine) prepared by the pentachlorophenyl ester $\operatorname{method}^{5}$ as shown in Figure 1. Even the crude polymer showed nearly the same pattern as the polymer synthesized by the active ester method, except for the small additional absorption at $2150 \mathrm{~cm}^{-1}$ due to the azide group. This additional absorption seems to be due not to the contamination of the material having an azide group such as DPPA, since the trial of the successive and exhaustive washings of the polymer with methanol or dioxane did not change the infrared (IR) spectrum. This can be attributed to the acyl azide at the $\mathrm{C}$-terminal of the polymer chain, suggesting that at least a part of the reaction proceeds through an azide coupling. This can also be interpreted on the assumption that the acyl azide, as an intermediate, can sometimes be firmly attatched to the polymer chain. The absorption at $2150 \mathrm{~cm}^{-1}$, however, disappears when the crude polymer is reprecipitated from DCA-water or treated in $1 \%$ aqueous triethylamine at $90^{\circ} \mathrm{C}$ for $1 \mathrm{~h}$, as shown in Figure 1, giving the completely same IR spectrum as that of the polymer made by the active ester method.

The amides I, II, and $\mathrm{V}^{7}$ absorption bands indicate that this polymer has mainly a $\beta$-conformation with a small amount of $\alpha$ - or random conformation. Two absorptions at $998 \mathrm{~cm}^{-1}$ and $977 \mathrm{~cm}^{-1}$ are due to the alternative -Ala-Glysequence. ${ }^{8}$ 


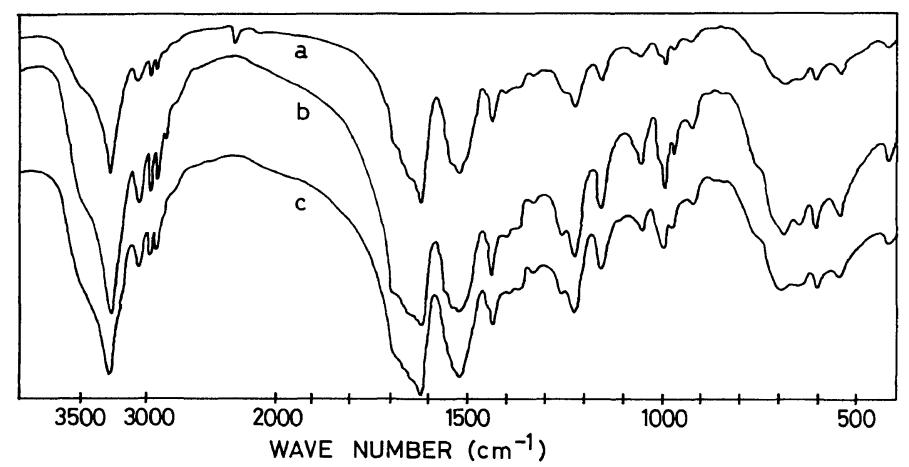

Figure 1. Infrared absorption spectra of poly(L-alanylglycine)s; a, polymer prepared by the DPPA method (crude); b, purified a by the reprecipitation from DCA-water; c, poly(L-alanylglycine) prepared by the pentachlorophenyl ester method.

\section{Purity of the Polymer}

Although poly(L-alanylglycine) made by the DPPA method showed the same IR spectrum as the polymer formed by the active ester method, the possibility of slight contamination due to side reactions or incomplete purification must be considered. For example, if polymerization by DPPA proceeds in part through azide coupling, as suggested by IR spectrum, there is the possibility of a Curtius rearrangement, which would induce the formation of urea bonds instead of amide bonds. There is also the possibility of contamination by the compound derived from DPPA. However, all of these possibilities have been ruled out by the following detailed purity checks. The phosphorus test for the reprecipitated polymer gave practically a negative result, although the crude polymer showed the presence of phosphorus. The elemental analysis and the amino acid analysis for the acid hydrolysate gave reasonable values. The acid hydrolysate of the polymer was also submitted to paper and silica-gel thin-layer chromatography, using two different solvent systems. The color development with ninhydrin or iodine detected only L-alanine and glycine with no additional spots. Also the optical rotation for the acid hydrolysate of a polymer showed reasonable values. The clear results from the chromatography procedures and the reasonable values obtained from elemental analysis, amino acid analysis and optical rotation should be sufficient to rule out any possibility of side reactions such as racemization or the Curtius rearrangement. Poly(Lalanylglycine) prepared by $\mathrm{H}-\mathrm{Ala}-\mathrm{Gly}-\mathrm{OH}$ poly- merization using the DPPA method can be considered pure provided suitable reaction conditions are employed.

However, the optical rotation for the acid hydrolysate of poly(glycyl-L-alanine) prepared by $\mathrm{H}-\mathrm{Gly}-\mathrm{Ala}-\mathrm{OH}$ polymerization gave a slightly lower value compared to that for the standard solution as described in the experimental section. It is not easy to conclude whether this result suggests a slight racemization, since the methodology for measuring the optical rotation of the acid hydrolysate does not seem to be very accurate in detecting a small degree of racemization. The possibility of the racemization in the polymerization of a peptide having an optically active amino acid at the C-terminal will be further investigated in detail.

Merits and Demerits of DPPA Method for the Synthesis of Sequential Polypeptide

The polymerization of amino acid or peptide by DPPA should probably be included in the category of the azide coupling method, or at least in part, on the basis of the IR spectrum of the polymer. Shioiri and Yamada $^{9}$ also suggested the possibility of azide coupling together with other possibilities for the reaction mechanism of the coupling reaction using DPPA. Magee and Hofmann proposed the polymerization method involving the use of the classical azide method for the synthesis of sequential polypeptides in $1949 .{ }^{10}$ They obtained satisfactory results; their method is excellent since it avoids the possibility of racemization. Although many other attempts have been reported for the polymerization 
of peptides, the only currently available method for the preparation of sequential polypeptide is the active ester method. ${ }^{11}$ The synthesis of the active ester, however, demands several chemical reactions. In particular, the synthesis of the active ester of long-chain peptides is fairly laborious. In the case of the DPPA method, peptides with free amino and carboxyl groups can be directly used in the polymerization reaction. This cuts down on the labor for the preparation of monomer peptides. Furthermore, the procedures for polymerization are very simple and easy. As for the molecular weight of the resultant polymers, the DPPA method gives results similar to those obtained with the active ester method. Thus the DPPA method may be regarded as very convenient and efficient for the synthesis of sequential polypeptides.

The suitable reaction conditions for the polymerization of L-alanylglycine determined in this study are general and applicable to the polymerization of other peptides. The syntheses of a number of other sequential polypeptides are now in progress.

Acknowledgement. The present work was supported by a Grant-in-Aid for Scientific Research from the Ministry of Education, Science and Culture of Japan. The authors should like to express their appreciation to Dr. Junzo Noguchi, Professor Emeritus of Hokkaido University, for his valuable advice.

\section{REFERENCES}

1. T. Shioiri, K. Ninomiya, and S. Yamada, J. Am. Chem. Soc., 94, 6203 (1972).

2. N. Nishi, B. Nakajima, N. Hasebe, and J. Noguchi, Int. J. Biol. Macromol., 2, 53 (1980).

3. F. H. C. Stewart, Aust. J. Chem., 19, 1067 (1966).

4. F. H. C. Stewart, Aust. J. Chem., 21, 2543 (1968).

5. B. Nakajima, K. Hirata, N. Nishi, and J. Noguchi, Int. J. Biol. Macromol., in press.

6. R. Katakai, M. Oya, K. Uno, and Y. Iwakura, J. Org. Chem., 37, 327 (1972).

7. T. Miyazawa, Y. Masuda, and K. Fukushima, $J$. Polym. Sci., 62, 562 (1962).

8. M. Asai, M. Tsuboi, T. Shimanouchi, and S. Mizushima, J. Phys. Chem., 59, 322 (1955).

9. T. Shioiri and S. Yamada, Chem. Pharm. Bull., 22, 855 (1974).

10. M. Z. Magee and K. Hofmann, J. Am. Chem. Soc., 71, 1515 (1949).

11. For example, J. Ramachandran, A. Berger, and E. Katchalski, Biopolymers, 10, 1829 (1971). 